\title{
Study on the Mechanism of Social Assistance and Precise Poverty Alleviation
}

\author{
Jianping Liu', Zhongyi Ding ${ }^{2}$ \\ ${ }^{1}$ Sichuan Agricultural University, Yaan, Sichuan, 625000 \\ ${ }^{2}$ Sichuan University, Chengdu, Sichuan, 610000
}

Keywords: Social Assistance, Precision Poverty Alleviation, Convergence Mechanism

\begin{abstract}
By 2020, the overall goal of poverty alleviation and development in China is to achieve "two worries, three guarantees", which is the comprehensive standard of poverty alleviation in China. Its content and our social assistance system projects complement each other. In order to better promote the effective connection between social assistance and precision poverty alleviation, this article takes Chongqing city as an example, through the investigation and discussion methods, grasp the status quo of social assistance in Chongqing, from the rescue object identification precision, rescue project arrangements accurate, Capital use precision, participation in the main body diversification, management mechanism to improve the five aspects of social assistance and precision poverty alleviation of the convergence mechanism.
\end{abstract}

\section{Introduction}

According to the goal of "Chongqing Municipal People's Government of Chongqing Municipal People's Government on the implementation of precision poverty alleviation", by the end of 2017, Chongqing will achieve 18 additional poverty-stricken counties, 1919 poor village sales, 165.9 million poor people out of poverty, basic Complete the task of poverty alleviation. As of July 2017 data show that Chongqing has nine poor counties in the hat, 1693 poor village sales, 154.9 million poor people out of poverty. To complete the goal of poverty eradication in 2017, Chongqing will further increase the employment of industry poverty alleviation efforts to achieve industrial development and social security, the temporary relief, poverty alleviation relocation of the seamless convergence, and enhance the hematopoietic function of poor areas.

\section{Achievements in the implementation of social assistance policies in Chongqing}

First of all, in the formulation of regulations, the relevant departments of Chongqing City, the implementation of the specific measures to implement social assistance, including the Chongqing Municipal People's Government issued the "further improve the implementation of the poor people to support the implementation of the system" (Yu Fu [2016] 47 (Chongqing Municipal People's Government and the Finance Bureau jointly issued a document on the further work on the medical aid work), Chongqing Municipal Civil Affairs issued a separate "on the poor people to do the work of the approval of the notice" (Chongqing people [2017] No. 88), Chongqing Municipal Bureau of Civil Affairs and Finance jointly issued a " (Yu Min [2016] No. 63), "on the issuance of Chongqing urban and rural community service center construction financial subsidy fund management approach notice" (Chongqing people [2016] 162), etc., from the system clearly identified social assistance Scope, clear departmental responsibility, standardize the use of funds and other content, and further improve the social assistance system in Chongqing.

Second, in the process of policy implementation, Chongqing City, "a reception, coordination," the social assistance work procedures. Social security, "a government, led by the government, led by the civil affairs department, education, housing, construction, employment, health care and other relevant functional departments to follow the" people-oriented, convenient masses, based on reality, integration of resources, Responsibility to implement, improve the mechanism, standardize the operation of "the working principle. To Fengjie County, Chongqing, for example, the county civil 
affairs bureau to strengthen the county Social Security Bureau, Wei Planning Commission, the organization and other departments of the communication and coordination, regular information comparison, strengthen the dynamic management to ensure that the object is accurate, 2017 1-6 Month on a total of 1592 non-compliance with the conditions of urban and rural subsistence allowances to stop processing.

Chongqing City, the functional departments of the social assistance project division as follows:

\begin{tabular}{|l|l|}
\hline Social assistance project & Corresponding main functional departments \\
\hline Minimum living guarantee & Civil affairs department \\
\hline Poor people support & Civil affairs department \\
\hline Disaster relief & Civil affairs department \\
\hline Medical assistance & Civil affairs department \\
\hline Education bailout & Education department \\
\hline Employment assistance & Human social security department \\
\hline Housing relief & $\begin{array}{c}\text { Land and housing management departments, urban } \\
\text { and rural construction sector }\end{array}$ \\
\hline Temporary relief & Civil affairs department, health care department \\
\hline
\end{tabular}

Chongqing municipal government attaches great importance to the convergence of social assistance and precision poverty alleviation, from the minimum living security project to the temporary relief, expect to establish a more effective convergence mechanism to adapt to the current situation of precision poverty alleviation, change the work of precision poverty and the way The In the specific convergence, the local government at all levels in Chongqing from the minimum living security project to explore the two convergence mechanism.

In 2015, the Chongqing Municipal Civil Affairs Bureau issued a document on "the standard of rural subsistence allowances and poverty alleviation" two-way "to play a low role in the protection of the end of the notice" (Yu Min Fa [2015] 76), " (Yu Min [2015] No. 80), and so on, respectively, "on the mobilization of social organizations and charitable forces to participate in poverty alleviation work" (Yu Min Fa [2008] 80) and other documents, respectively, On the minimal assurance, medical assistance, temporary relief and other projects to implement the docking of precision poverty. Among them, especially for rural subsistence allowances and precision poverty alleviation work put forward higher requirements.

\begin{tabular}{|c|c|}
\hline To protect the task of poverty & $\begin{array}{c}\text { And docking measures with precision poverty } \\
\text { alleviation }\end{array}$ \\
\hline Clear the scope of the object & $\begin{array}{c}\text { Rural minimum standard and poverty alleviation } \\
\text { standards "two-in-one" }\end{array}$ \\
\hline $\begin{array}{c}\text { Standardize the procedures for } \\
\text { determining the low level of the object }\end{array}$ & $\begin{array}{c}\text { Based on the existing information on the establishment } \\
\text { of poor households, clear "five-step process" that } \\
\text { procedures }\end{array}$ \\
\hline
\end{tabular}

\section{The plight of the implementation of social assistance policy in Chongqing}

The object of the object of the lack of awareness of the development of relief projects. In view of the current situation, due to the refinement of social assistance projects, and the interrelationship between the various projects, it is necessary to consider the respective standards of each project, but also take into account the interdependence between projects, the need for local governments to further rationalize the relationship between the various projects, Identify the key, each break. At present, Chongqing City in the identification of standard-setting, the main focus on the minimum living security, poor people support, temporary rescue several projects, and for the new era of 
education, housing assistance, employment assistance in several aspects of the lack of in-depth and clear provisions, These three relief relative to other salvage, the development of relief features obvious, although the project may be the subject of economic difficulties such as subsistence allowances and other projects are obvious, but the rescue has a preventive function, and to help families and individuals future Development has an important impact, the effectiveness of the rescue may be more obvious.

The lack of assistance to identify the process of communication with grassroots people. Chongqing Municipal Civil Affairs Bureau, "on the depth of the implementation of the views of the implementation of poverty," clearly put forward the norms of low-cut object identification procedures, the implementation of the "five-step process" that procedures, medical assistance to implement the "four-step" process, and are clearly defined, Identify the procedure open, fair and transparent, for those who do not meet the conditions need to explain the reasons to the applicant. Through the grassroots research found that the grassroots civil affairs departments to do a basic, open, just object to meet the basic requirements of the document. But in the process of identification and communication with the masses and deep enough. First, before the identification, and the applicant neighbors and the villagers do not communicate enough, but also missed the policy and the criteria for interpretation of the masses of the opportunity, resulting in the identification, some people have questions on the results. Second, after identification, for those who can not identify the applicant did not give a reasonable reason, for the list of identified only published list, did not specify the success of the application based on the standard.

Social assistance, "a government, led by the government, led by the civil affairs department, education, housing, construction, employment, health care and other relevant functional departments, from the various functional departments of Chongqing, the division of social assistance projects can be found, large Part of the social assistance projects need to lead the civil affairs sector, and with the new poverty alleviation work trends, social assistance will become the government and civil affairs departments thirteen five plan in the latter part of the work of the focus. At present, Chongqing focus on strengthening the grassroots civil affairs departments, focusing on strengthening the township level civil affairs department staff configuration and training. However, most of the grassroots civil servants in Chongqing are lacking Internet knowledge. In the background of "Internet + government", it is not conducive to the development of the work. In the field of research found that a street civilian office in Chongqing, a total of six staff, and skilled in the operation of only two people, far from being able to meet the current needs of the current civil work. This phenomenon is more prominent in other parts of Chongqing, especially in remote areas of township civil affairs departments.

\section{Explore the social assistance and precision poverty alleviation mechanism}

In this paper, Chongqing City, for example, summed up the city of Chongqing in the social assistance policy and precision poverty alleviation convergence of the existing experience, learn from domestic and foreign experience, from the rescue object accurate, accurate project arrangements, precise use of funds, participation in the main precision, Precision five aspects to explore the social assistance and precision poverty alleviation of the convergence mechanism, through social assistance "precision" convergence precision poverty.

To the minimum living security assistance as a breakthrough, docking precision poverty alleviation plan poor households. According to the "Interim Measures for Social Assistance" on the eight social assistance project object, in addition to the disaster relief and temporary assistance with sudden characteristics, the other six relief projects are related to the minimum living security or poor people to help families, Which, in particular, the minimum living security as the basis, therefore, in determining the object of social assistance, the minimum living security object should be identified in the work ahead. And the minimum insurance policy is an important implementation of poverty alleviation projects, therefore, to confirm the object of social assistance can be docked precision poverty alleviation plan poor information, improve work efficiency.

Perfecting the Legal Mechanism of the Procedure of Social Assistance. On the one hand, before 
the confirmation and confirmation, should be with the applicant neighbors and the village residents to conduct interviews and interviews to understand the applicant's real situation, do a good job in advance work, to reduce the rate of reporting after the masses to a minimum. At the same time, in the publication of the object, it should be published basis, so that the masses in-depth understanding of the standard, to dispel the hearts of the doubts. On the other hand, the object should be informed of the reasons for the unqualified, and to meet the conditions of other relief projects to give the correct guidance. To correctly guide the interests of the masses demands to consolidate the party and the government at the grassroots level of legitimacy.

Chongqing City, "on the implementation of precision poverty alleviation of the implementation of opinions" for precision poverty alleviation of the infrastructure construction, industry support, education, health care, employment, low security and other eight poverty alleviation special, which, education, health, employment, The poverty alleviation and poverty alleviation project and measures can be docked with the social assistance of the education assistance, medical assistance, employment assistance, minimum living security assistance, housing assistance, in the relevant relief measures have been further improved on the basis of.

Social assistance measures should be based on different projects to explore more ways to rescue. So far, there are still many grassroots people think that precision poverty alleviation and government assistance is to "collar money", etc., by, to the phenomenon still exists. Such as the minimum living security to implement the difference between the rescue, medical assistance should be in the rescue object to produce medical expenses when the relief policy, employment assistance can be recommended through employment, strengthen the employment skills training and other measures try to rescue, for no reason to accept employment recommendations and arrangements for the rescue object, should cancel its salvage qualification.

The use of capital mainly refers to the "rescue funds from where", "rescue who", "how to rescue" problem.

First of all, the source of funds, to precision poverty alleviation funds, most of the funds are mainly government financial investment, especially the central financial transfer payments and provincial financial investment. At present, China's social assistance is facing a bottleneck is that most local governments to put their hopes on higher levels of government, especially the central government transfer payments, the reason is that all levels of government financial responsibility is not clear. Therefore, we can learn from the experience of foreign developed countries, a clear local governments at all levels of social assistance projects on the proportion of financial investment, so that the source of funds to stabilize.

Second, the use of funds in the object, do a good job to determine the accuracy of the object of relief, strict control of funds issued to ensure that the rescue funds used to serve the rescue object.

Finally, in the use of funds, combined with the precise arrangements for the project, the rational use of relief funds. Specific can be divided into cash relief and non-cash relief in two ways. Among them, the minimum living security is all the relief projects, in order to directly grant the rescue object cash relief project. Other relief projects should explore non-cash relief methods, through employment training, loan discounts, medical claims and other non-cash relief, to develop, sustainable concept of relief.

The state encourages social forces such as units and individuals to participate in social assistance through the donation, the establishment of support projects, the establishment of service agencies, the provision of volunteer services, etc., to form a diversified mode of social assistance.

"A reception, coordination" by the government-led, civil affairs sector led, education, housing, construction, employment, health care and other relevant functional departments with. Through the division of functions of the various functions of the various departments are mainly responsible for social assistance projects. In this article, this article would like to further emphasize that social assistance and precision poverty alleviation complement each other, therefore, around the Poverty Alleviation Office or Poverty Alleviation Bureau (around the name of the different) should be involved in social assistance projects, from institutions and personnel to achieve convergence The real connection between social assistance and precision poverty alleviation. 
"Interim Measures for social assistance" clearly pointed out: the local people's governments at or above the county level of social assistance in the specific services through commission, contracting, procurement, etc., to the social forces to buy services. Chongqing further pointed out: mobilization and cohesion charity to participate in poverty alleviation, the formation of government, market, social support each other, special poverty alleviation, industry poverty alleviation, social poverty alleviation "trinity" poverty alleviation pattern. Chongqing issued "on the extensive mobilization of social organizations and charitable forces to participate in poverty alleviation work of the notice" (Yu Min Fa (XXun ) 80), to explore the construction of social organizations to participate in social assistance and poverty alleviation work convergence mechanism. The program in the specific implementation process, due to geographical differences and the effect is different. In the distance from the central city, the power of social organizations is limited. Here, this article has the following suggestions: First, change the old ideas of social organizations to rescue the way. Social organizations to participate in the rescue is not equal to the material donation, colleges and universities can play its scientific research advantages, help industry and agricultural technology relief, to help rescue the object to enhance the ability of social workers can provide psychological counseling and volunteer services to enhance the physical and mental health of the object. Second, standardize the establishment of social organizations system, expand the scale of social organizations. Third, clear social work orientation, training high-quality social workers talent team.

\section{The precision of the management mechanism mainly refers to the standardization of the social assistance management system.}

The precise content of the management mechanism mainly refers to the system standardization of the rescue system, such as the standard of rescuing the rescue object, the way of rescue, the principle of relief and so on. At present, China's relevant legal provisions only "Interim Measures for Social Assistance", "Urban Residents' Minimum Living Security Ordinance", which is the document released in 1999, and the rural minimum living security system construction is in 2007, by the State Council Issued a document, generally launched throughout the country.

It can be seen that the degree of social assistance system in our country is far from satisfying the demand of reality. Especially in the 2014 State Council issued the "Interim Measures for Social Assistance", the refinement of the social assistance projects, and stressed the social assistance and precision poverty alleviation of the convergence of the existing "Urban Residents Minimum Living Security Ordinance" was developed in 1999, With the current socio-economic conditions and the background of a certain degree of access. Therefore, for the local government, according to local conditions, introduced to adapt to the region's social assistance management approach, especially on the salvage standards, relief and other relief content of the rescue law.

The object of the double audit, strict checks and procedures and standards. Township government and street office to set up a comprehensive window of social assistance, by the township and the street for preliminary examination, will meet the conditions to be identified object submitted to the county civil affairs departments and Poverty Alleviation Office, the Ministry of Civil Affairs Department and Poverty Alleviation Office in other relevant departments Cooperate with the verification of the applicant's tax, real estate, household income and other information, for the township government and the streets do not meet the conditions of the application to be rejected.

Improve the open mechanism of government affairs, focusing on the village (home) services to play a public advantage of social supervision. The social assistance in the context of precision poverty alleviation has been highly concerned by all sectors of society. Therefore, it is necessary to make public the policy of salvage and poverty alleviation. Second, we should make public the criteria, procedures and results of the rescue object. The use of funds; four to make good use of the advantages of the Internet to enhance the breadth and depth of government affairs.

Finally, the social rescue supervision and management should be combined with the department responsibility system, according to the social assistance project government functions division of labor division of responsibility. Only by implementing the responsibility can the supervision be 
implemented.

\section{Acknowledgements}

Project Source: Sichuan Rural Development Research Center 2016 Project "Empirical Study on the Distribution of Poverty Alleviation and Distribution of Villages and Towns in the View of Power Supervision"

Project No.: CR1708; Sichuan Agricultural University 2017 Double Support Program Project Achievement

\section{References}

[1] State Council. Interim Measures for Social Assistance [Z] .2014-2-21.

[2] Chongqing Municipal Civil Affairs Bureau. On the depth of the implementation of the policy to promote poverty alleviation [Z] .2016-1-22.

[3] Chongqing Municipal People's Government of Chongqing Municipality on the implementation of precision poverty alleviation [Z] .2015-5-18.

[4] Zheng Ruiqiang. Design and Development Guarantee of Family Social Assistance Mode in "Expenditure Poverty" [J]. Agricultural Economics, 2016, (2).

[5] Gao Hai. Reflection and Reconstruction of Rural Minimum Living Guarantee Line in China [J]. Journal of Hunan Agricultural University, 2008,9 (4).

[6] Cai Hui. Swedish social assistance system and its enlightenment to China [J]. Chinese Journal of Finance and Economics, 2009,25 (3).

[7] Wang Kai. Active rescue of China to explore: precision poverty alleviation and subsistence allowances [J]. Journal of Fujian Administration Institute, 2016, (6). 